\title{
Intertied AC-DC Hybrid System Power Sharing Through Intelligent Droop Controller
}

\author{
Preeti Gupta \\ Electrical Engineering Department \\ Maulana Azad National Institute of Technology \\ Bhopal, India \\ preeti.irig@gmail.com
}

\author{
Pankaj Swarnkar \\ Electrical Engineering Department \\ Maulana Azad National Institute of Technology \\ Bhopal, India \\ p_swarnkar@yahoo.co.in
}

\begin{abstract}
The result of DG clustering is the hybrid power system while further clustering forms the intertied hybrid power system. Interfacing of intertied hybrid power system requires an interlinking converter with a legitimate power administration and control system. In contrast to individual hybrid power system (HPS), power administration of the intertied hybrid system is more complex. Autonomous droop strategy is appropriate for the intertied hybrid system where communication links are not possible. This paper proposes a new topology for control in intertied hybrid system where two hybrid power systems are connected to each other through interlink power converter. Evaluated frequencies in different HPSs can diverse. In order to manage power flow a power management strategy with consideration characteristics of common bus, a $\mathbf{P}_{\mathrm{DC}}$ $\mathrm{v}_{\mathrm{DC}}{ }^{2}$ method is proposed, and compared with conventional droop, to realize power sharing among HPS. The practicability of the proposed power sharing method is realized in MATLAB/Simulink platform.
\end{abstract}

Keywords-intertied hybrid system; power sharing; intelligent controller

\section{INTRODUCTION}

Concerns about natural outflow from centralized power plants have extended excitement for DG establishment, despite the fact that DG infiltration in power structures is limited due to specific reasons like reliability necessities [1]. Hybrid power Systems (HPSs) are required to work both in grid connected power systems and standalone modes to fortify dependability and power quality [2]. Grid accountability to maintain the system voltage and frequency with appropriate sharing of power in autonomous system is desirable [3-6]. The intertied hybrid system is a focus of research due to its high reliability and flexibility with integration of renewable energy sources. In this paper, the intertied hybrid system composed of different voltage and different frequency HPS with either DC or AC source is considered. Hence the intertied hybrid system can utilize the important characteristics of both DC and AC HPS. In contrast to individual HPS, power management of the intertied HPS is more intricate because of interfacing AC and DC HPS. Hence the design of a power sharing controller for exploiting the features of intertied HPS is a major challenge. For diverse applications, the configuration of intertied HPS can be distinctive. The conventional intertied HPS normally includes one AC HPS and one DC HPS. Concentrating on this issue this paper proposes a new control method for intertied HPS with two HPSs of different frequency. Some fast communication methods by using master-slave techniques is discussed in $[7,8]$, but due to requirement of communication links the system is not more reliable. While designing a controller for a VSC based hybrid system without communication link some issues have to be considered and conventional techniques mightbe inappropriate. In $[9,10]$, authors discussed conventional droop control, where enhanced DC current sharing is obtained with suppression of DC voltage deviations by low bandwidth communication signals but it excludes time delay effects. Moreover, distributed secondary control in [11] overcomes the shortcoming of the conventional droop. Different power management strategies of hybrid microgrids are discussed in [12]. From the perspective of power balance $\mathrm{v}_{\mathrm{dc}}^{2}-\mathrm{p}_{\mathrm{dc}}$ droop control is developed in [13]. Power sharing among intertied HPS with artificial intelligence is proposed in [14] to enhance the operating battery lifetime. To overcome the limitations of previously mentioned methods an intertied HPS with multiple HPS is considered in this paper. Proposed controller adopts decentralized controller which enhances the reliability of the system. The attractive feature of the control method is the linear relation between $v_{d c}{ }^{2}$ and $P_{d c}$. The proposed control assures power sharing in coordination with voltage and frequency support. Also the control scheme is appropriate for different HPS capacities. The effectiveness of the proposed power sharing control is verified by SPS toolbox.

\section{INTERTIED HYBRID SYSTEM TOPOLOGY}

The proposed scheme for intertied HPS is shown in Figure 1. The intertied HPS is composed of multiple AC HPS of different rated frequencies and different rated DC HPS. Intertied HPS are strictly free to have their own voltage and frequencies that better match with their sources and load. Some countries have rated frequency of $50 \mathrm{~Hz}$, others $60 \mathrm{~Hz}, 400 \mathrm{~Hz}$ frequency is found in aircraft supply networks. Therefore different conditioned HPS interlinking is necessary for appropriate power sharing and load adaptability. The higher system inertia of the intertied HPS keeps the system stable under perturbation, while the feature of lower reserve requirement reduces the startup capital cost which includes the cost of inserting power converters. Addition of power 
converters is therefore a universal approach more likely to draw researcher's interest. Some of already existing HPSs include standalone power networks for electric ships, electric aircrafts and electric vehicles with their own preferred voltages and frequencies even though they are usually compactly small. The thought of clustering and interlinking has, in fact, been recently promoted by research, concentrating on the division of a local area network into subzones/ clusters of either the same or different voltage levels. The objective there is to enhance system reliability, security and efficiency by minimizing transmission and distribution losses. MPPT can be applied for the DGs having intermittent nature. Different IPCs are employed to interconnect different HPSs according to rating. Interlinking converters play an important role in providing bidirectional energy transfer between HPSs. The intertied HPSs can be connected to the AC utility mains through an intelligent switch.

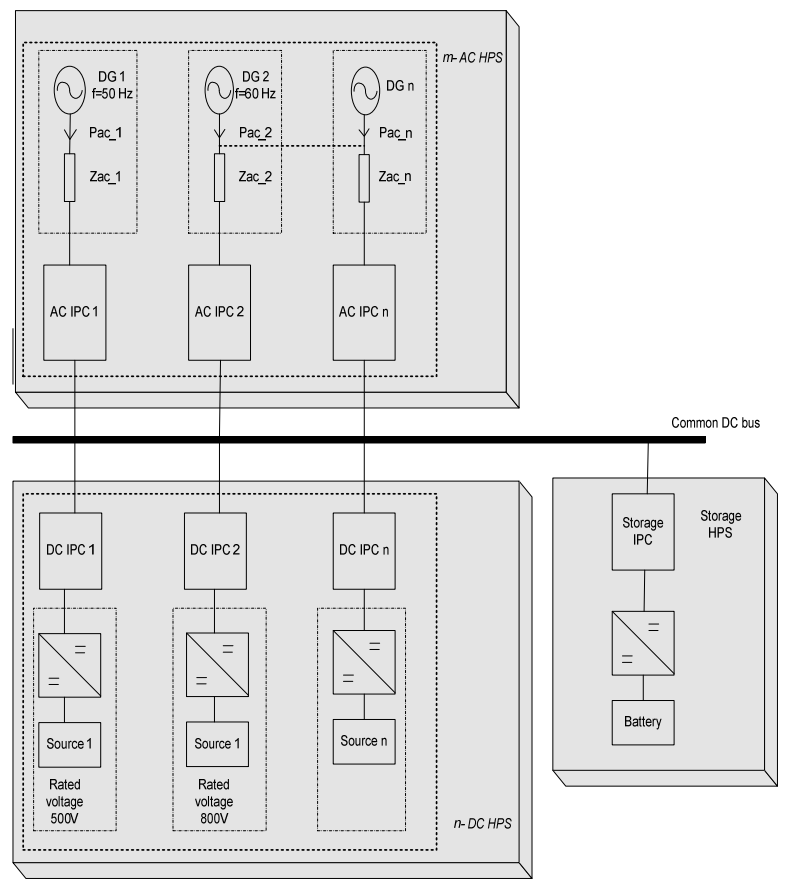

Fig. 1. Intertied hybrid system topology

A standalone system should be capable of fulfilling the load demand. The sources will deliver the power depending upon the information received through explicit communication links without overstressing themselves. The problems of cost increase and single point failure can be resolved by droop control, where adjustment of voltage magnitude and frequency is to be sensed by each HPS. The intertied HPS considered in this paper is in standalone mode, however the controlling of standalone system is more complex when compared to grid connected system.

\section{AUTONOMOUS CONTROL FOR INTERTIED HYBRID SYSTEM}

Droop scheme has been extensively used for power sharing in conventional power generation which is now extended to intertied HPS. The storage system satisfies the load demand under the power supply failure. The function of the storage system is to sustain the common DC link voltage with proper power sharing. The battery is connected to common bus through a DC-DC boost converter. Since the intertied HPS constitutes many HPSs including storage system, they need to be connected to common bus with IPCs. The main role of IPC is to manage the power sharing and maintain constant voltage. When power failure occurs and storage system is providing the power to loads the relation between $i_{L}$ and $v_{d c}$ is not linear:

$$
i_{L} \alpha \frac{d v_{d}}{d t}
$$

Due to nonlinear relation between current and voltage conventional droop control will not provide satisfactory performance. To look into power balance scenario the relation between $\mathrm{P}_{\mathrm{dc}}$ and $\mathrm{v}_{\mathrm{dc}}{ }^{2}$ is linear which motivatesthe application of a new droop strategy for improved performance. The control strategy involves inner and outer loops, where the controlling of $\mathrm{v}_{\mathrm{dc}}^{2}$ is achieved by inner loop control by tracking the reference generation by outer loop. The power sharing is achieved by outer loop control by $P_{d c}-v_{d c}^{2}$ droop. The inner loop static error elimination is done by PI controller followed by proportional controller to advance the system damping and reliability. The control law for $P_{d c}-v_{d c}{ }^{2}$ droop is expressed as

$$
v_{d c}^{r e f^{2}}=v_{c b}^{*^{2}}-r\left(P_{d c}-P_{d c}^{*}\right)
$$

where $r, v_{c b}, v_{d c}^{r e f}, P_{d c}$ and $P_{d c}{ }^{*}$ are the droop coefficient, common bus voltage, reference output voltage, DC power and reference DC power respectively.Figure 2 shows the simplified circuit of the proposed droop control where $v_{c b}$ is the common bus voltage and $R_{\text {line }}$ is the line resistance. DC power can be calculated as

$$
P_{d c}=\frac{v_{c b}^{*^{2}}+r P_{d c}^{*}-v_{d c} v_{c b}}{R_{\text {line }}+r}
$$

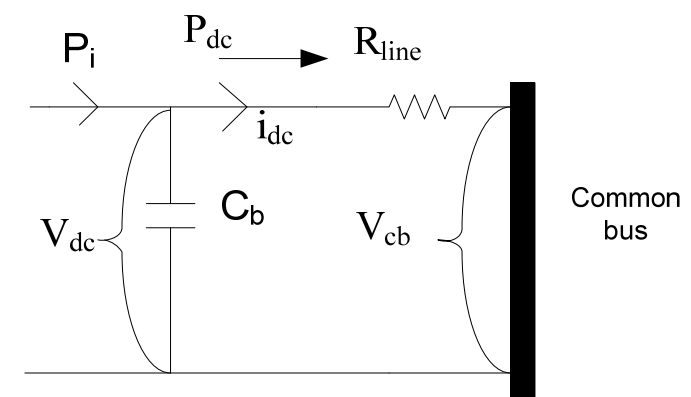

Fig. 2. Circuit simplification for proposed droop control

To simplify the equation assume $G=v_{c b}^{*^{2}}+r P_{d c}^{*}$, and $r>>R l_{\text {ine }}$ then (3) can be rewritten as

$$
P_{d c}=\frac{G-v_{d c} v_{c b}}{r}
$$




$$
\frac{r P_{d c}}{v_{c b}}=G-v_{d c}
$$

After solving the above equations $\mathrm{P}_{\mathrm{dc}}$ can be written as

$$
P_{d c}=\frac{G-v_{c b}^{2}}{r}
$$

The equation implies that $P_{d c}$ is inversely proportional to $r$ and the matching of $P_{d c}$ and $r$ is according to storage capacity. Droop control method for HPS 1 and HPS 2 is based upon the conventional method. In (7)-(10) $x$ is DG unit number, fis the frequency, $V$ is terminal voltage , $P$ is active power and $Q$ is reactive power generation respectively.

$$
\begin{aligned}
& f_{x}=f_{\text {max }}-m_{x} P_{x} \\
& m_{x}=\frac{f_{\text {max }}-f_{\text {min }}}{P_{x, \text { max }}} \\
& v_{x}=v_{\text {max }}-\eta_{x} P_{x} \\
& \eta_{x}=\frac{v_{\text {max }}-v_{\text {min }}}{Q_{x, \text { max }}}
\end{aligned}
$$

where $m_{x}$ and $n_{x}$ are active and reactive droop coefficients.In this paper, four HPSs are considered intertied by interlinking converters. Droop control has the feature of active power flow from under-loaded to overloaded HPS. Droop control works under three conditions: under loading, over loading and heavy overloading.Conventional droop control for the proposed system is shown in Figure 3 where interlinking converters are implemented with two six switch converters. Each interlinking converter's power is equal and opposite tothe others'. Outer loop consists of two PI controllers for active and reactive power errors. The two HPSs of different frequencies are connected to the common DC bus. Control strategy has two loops, inner and outer loop. The inner loop to tracks the reference to be generated by the outer loop. The reference value generated by the outer loop can be expressed as

$$
\begin{aligned}
& f^{r e f}=\left(f^{*}+\delta f\right)+m\left(P^{*}-P\right) \\
& v^{r e f}=V^{*}+n\left(Q^{*}-Q\right)
\end{aligned}
$$

Here $f^{r e f}$ and $V^{r e f}, f^{*}, V^{*}, P^{*}, Q^{*}, P, Q, m$ and $n$ are the reference output frequency and voltage, rated frequency, rated voltage, rated active power, rated reactive power, actual active and reactive power and droop coefficients respectively. $\delta f$ is the change in the frequency due to change in load among different HPSs.

For interconnection of DC HPSs, high voltage side is connected to common bus. The control procedure with two loops has $i_{d c}-v_{d c}$ characteristics to generate reference signal. The outer loop is used to track the reference signal. The control method follows the relation as

$$
v_{d c}^{r e f}=\left(v_{d c}^{*}+\delta v\right)-r i_{d c}
$$

where $V_{d c}{ }^{r e f}, V_{d c}{ }^{*}, r, i_{d c}, \delta V$ are reference DC voltage, rated DC voltage, droop coefficient, actual output DC current and change in the voltage corresponding to change in the load among different HPS.
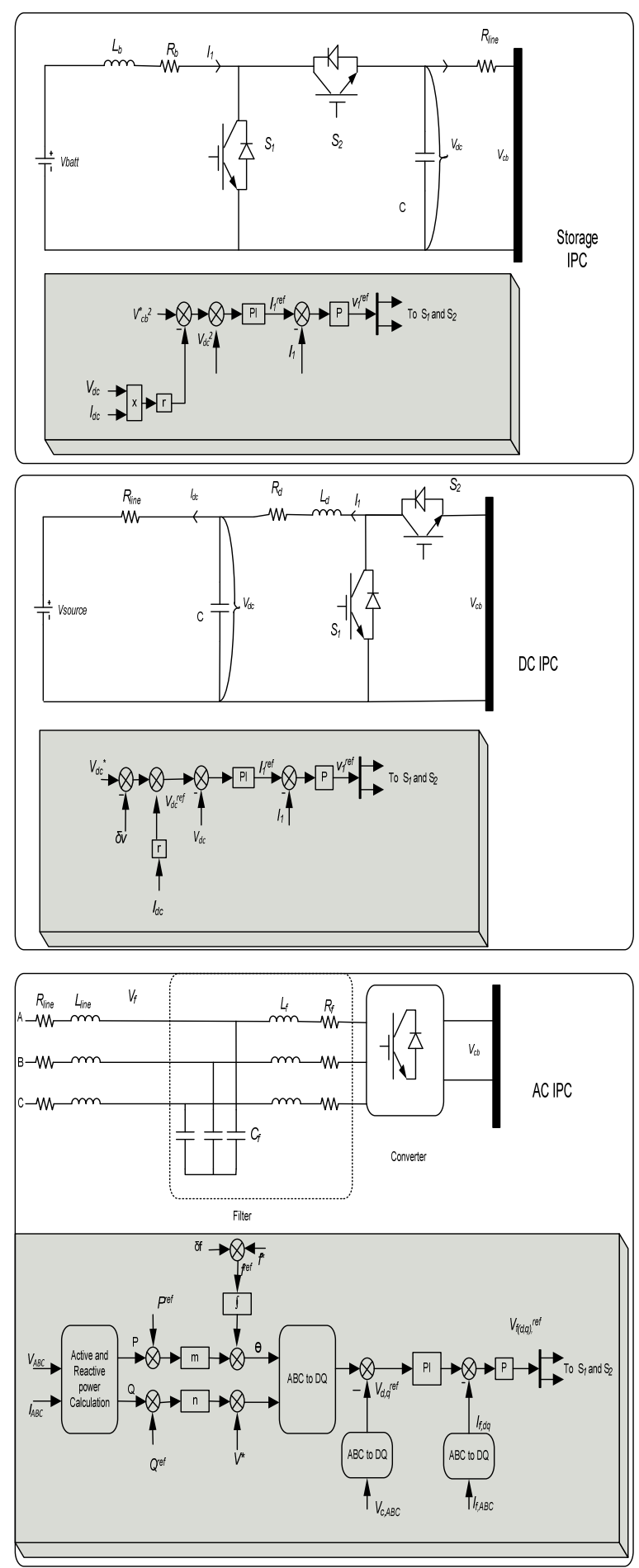

Fig. 3. Controller for intertied hybrid system 


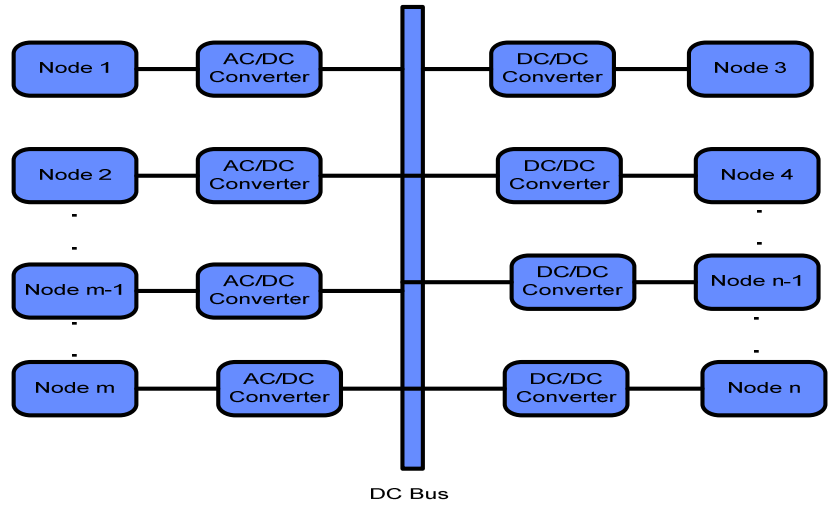

Fig. 4. Interconnection of IPC in intertied hybrid system

\section{POWERSHARING AMONG DIFFERENT HPSS}

Section III focused on the control method for an individual HPS. Power interaction among different HPSs in a intertied system is more complex and is analyzed in this section. The coordinated control among individual HPSs ensures power fluctuations divided in all HPSs whether DC or AC. Enhanced performance can be achieved by supporting all HPSs. All HPSs are droop controlled, which implies changes in frequency and DC voltage according to change in load demand. The change in DC voltage for DC HPS and frequency for AC HPS represents power changes inside the DC or AC HPS. AC and DC IPCs absorb power from or release power to the common bus, which represents changes in the whole intertied hybrid system. Additionally frequency relates to power of AC loads and DC voltage relates to power of DC loads. Above mentioned changes in frequency, DC voltage and common bus voltage require coordinated control for $\mathrm{AC}$ IPC and DC IPC. The control law can be expressed as

$$
\begin{aligned}
& \delta f_{m}=\left(k_{p, m}+\frac{k_{i, m}}{s}\right)\left[\frac{\left(v_{c b}-v_{c b}^{*}\right)}{v_{c b}^{\max }-v_{c b}^{\min }}-\alpha_{m} \frac{f_{m}-f_{m}^{*}}{f_{m}^{\max }-f_{m}^{\min }}\right] \\
& \delta v_{n}=\left(k_{p, n}+\frac{k_{i, n}}{s}\right)\left[\frac{\left(v_{c b}-v_{c b}^{*}\right)}{v_{c b}^{\max }-v_{c b}^{\min }}-\alpha_{n} \frac{v_{d c, n}-v_{d c, n}^{*}}{v_{d c, n}^{\max }-v_{d c, n}^{\min }}\right]
\end{aligned}
$$

where $\delta f_{m}$ and $\delta v_{k}$ are the coordinated control signal for IPC of $m$-th AC HPS and IPC of $n$-th DC HPS respectively. Proportional and integral constants for respective AC or DC HPS are given by $k_{p}$ and $k_{i} . \alpha_{m}$ and $\alpha_{n}$ are the correction coefficients in consideration to capacity of $m$-th and $n$-th AC and DC HPS respectively. $f_{m}, f_{m}{ }^{*}, f_{\text {mmax }}$, and $f_{m \text { min }}$, are actual frequency, rated frequency, maximum and minimum allowable range of frequency, $v_{c b}, v_{c b}, v_{c b \max }$ and $v_{c b \min }$ are actual common bus voltage, rated common bus voltage, maximum and minimum allowable range of common bus voltage respectively.

Considering the capacity of the AC and DC HPS, if one HPS has high capacity compared to other HPSs then the weak HPS contribution to the system is less and strong HPS should absorb or release power. In view of the above coordination the correction coefficient is proposed. The correction coefficient of $p$-th HPS can be calculated as

$$
\alpha_{p}=\left(\frac{H_{p}^{\text {total }}}{H^{\text {total }}}\right)^{-1} \frac{H_{p}^{c}}{H_{p}^{\text {total }}}
$$

Where $H_{p}^{\text {total }}$ and $H_{p}^{c}$ and are total and critical load capacity of $p^{\text {th }}$ HPS and $H^{\text {total }}$ is the total capacity of intertied HPS. It is clearly depicted from (16) that, for small capacity and high amount of critical loads, correction coefficient is large and subsequent changes in DC voltage and frequency are small. Synchronization between change in voltage and change in frequency proves the efficacy of the proposed method. Under steady state condition the relation between voltage and frequency considering capacity of the system is given by (17):

$$
\frac{\left(v_{c b}-v_{c b}^{*}\right)}{v_{c b}^{\max }-v_{c b}^{\min }}=\alpha_{p} \frac{f_{p}-f_{p}^{*}}{f_{p}^{\max }-f_{p}^{\min }}
$$

Figure 5 shows the corrected relative changes in AC frequency and DC voltage for the proposed control algorithm. The feedback variables are positioned at IPCs to share the coordinated power and can be realized to improve the reliability of the system.
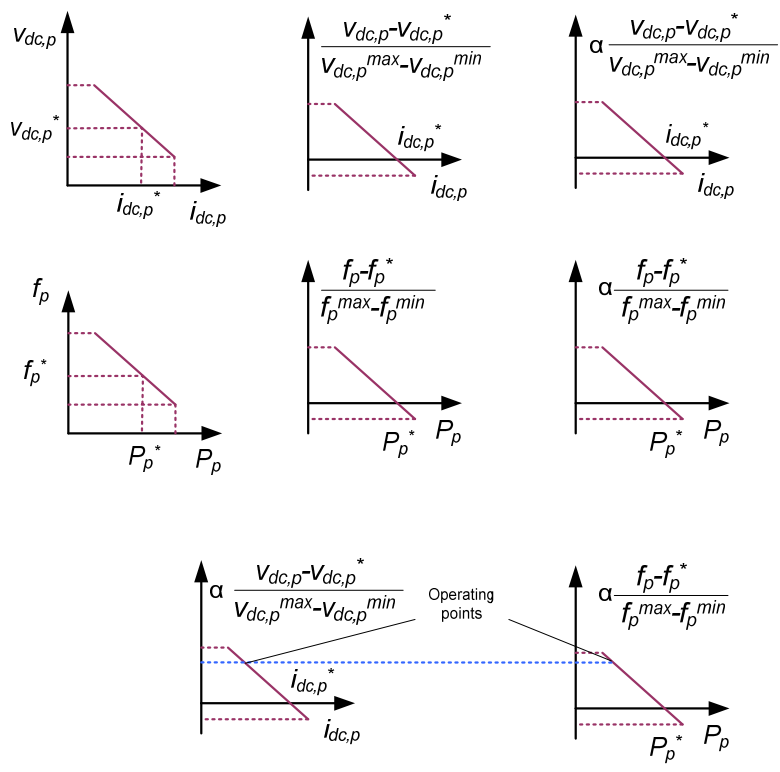

Fig. 5. Corrections for Coordinated Power Control

\section{RESULTS AND DISCUSSION}

The simulation was performed in MATLAB/Simulink using building blocks from SPS toolbox. The rated AC voltage of the $\mathrm{HPS}_{1}$ and $\mathrm{HPS}_{2}$ is $311 \mathrm{~V}$ with frequency $60 \mathrm{~Hz}$ and $50 \mathrm{~Hz}$ respectively. The permissible variation range of the frequency is $\pm 0.5 \mathrm{~Hz}$ and $\pm 0.6 \mathrm{~Hz}$ respectively. The rated DC voltage of the $\mathrm{HPS}_{3}$ and $\mathrm{HPS}_{4}$ is $375 \mathrm{~V}$ and $380 \mathrm{~V}$ respectively. The allowable variation range of the DC voltage is $\pm 25 \mathrm{~V}$. The rated load power of $\mathrm{HPS}_{1}, \mathrm{HPS}_{2}, \mathrm{HPS}_{3}$ and $\mathrm{HPS}_{3}$ are $180 \mathrm{KW}$, $130 \mathrm{KW}, 80 \mathrm{KW}$ and $70 \mathrm{KW}$ respectively. The storage HPS maintains the DC voltage of the common bus, whose rated voltage is $1000 \mathrm{~V}$. The rated voltage of the battery is $370 \mathrm{~V}$. The 
allowable variation range of the common bus voltage is $\pm 50 \mathrm{~V}$. The parameters of storages, IPC $1, \mathrm{IPC}_{2}, \mathrm{IPC}_{3}$ and $\mathrm{IPC}_{4}$ and are introduced in detail in Table I.

TABLE I. CONTROLLER PARAMETERS

\begin{tabular}{|c|c|c|}
\hline \multirow{2}{*}{ Controller } & \multicolumn{2}{|c|}{ HPS and IPC controller } \\
\hline & Controlling Parameter & Value \\
\hline Battery & Battery voltage & $600 \mathrm{~V}$ \\
\hline $\begin{array}{l}\text { Common } \\
\text { Bus }\end{array}$ & $\begin{array}{l}\text { Rated Common bus } \\
\text { voltage }\end{array}$ & $1000 \mathrm{~V}$ \\
\hline \multirow{6}{*}{$\begin{array}{l}\text { Voltage } \\
\text { controller }\end{array}$} & Storage $K_{p}$ & $0.0007 \mathrm{~A} / \mathrm{v}^{2}$ \\
\hline & Storage $K_{i}$ & $0.07 \mathrm{~A} / \mathrm{v}^{2}-\mathrm{s}$ \\
\hline & IPC $3 \& 4 \mathrm{~K}_{\mathrm{p}}$ & $0.6 \mathrm{~A} / \mathrm{v}^{2}$ \\
\hline & IPC $3 \& 4 K_{i}$ & $50 \mathrm{~A} / \mathrm{v}^{2}-\mathrm{s}$ \\
\hline & IPC $1 \& 2 \mathrm{~K}_{\mathrm{p}}$ & $0.8 \mathrm{~A} / \mathrm{v}$ \\
\hline & IPC $1 \& 2 \mathrm{~K}_{\mathrm{i}}$ & $100 \mathrm{~A} / \mathrm{v}-\mathrm{s}$ \\
\hline \multirow{2}{*}{$\begin{array}{r}\text { Current } \\
\text { Controller }\end{array}$} & Storage $\mathrm{K}_{\mathrm{p}}$ & $8 \mathrm{v} / \mathrm{A}$ \\
\hline & IPC $3 \& 4 \mathrm{~K}_{\mathrm{p}}$ & $3 \mathrm{v} / \mathrm{A}$ \\
\hline \multirow{4}{*}{$\begin{array}{l}\text { Coordinated } \\
\text { Power control }\end{array}$} & Coeffiecient & $\alpha_{1}=4, \alpha_{2}=0.75$ \\
\hline & $\mathrm{K}_{\mathrm{p}}$ & $0.03 \mathrm{~Hz}$ \\
\hline & $\mathrm{Ki}$ & $3 \mathrm{~Hz} / \mathrm{s}$ \\
\hline & Frequency & $\mathrm{f}_{1}=60 \mathrm{~Hz}, \mathrm{f}_{2}=50 \mathrm{~Hz}$ \\
\hline
\end{tabular}

To verify the proposed control, the dynamics of the intertied hybrid system operation states of the $\mathrm{HPS}_{1}$ are changed while other HPS states were kept stable. The system works in islanded mode under 2 states where state- I and stateII represents the rated state and variable state respectively. In state-II, load increases from $130 \mathrm{~kW}$ to $180 \mathrm{~kW}$ under the rated $\mathrm{AC}$ frequency and voltage. Figure 6 shows the dynamics of the intertied hybrid system with the proposed control with changes in operation states of the $\mathrm{HPS}_{1}$. Figure 6(a) shows the load power where load at $\mathrm{HPS}_{1}$ is suddenly increased from $180 \mathrm{Kw}$ to $260 \mathrm{KW}$. The AC frequencies are changed in coordination, which shows that AC and DC HPSs support each other. In state II, the load power of $\mathrm{HPS}_{1}$ increases, consequently AC frequency decreases.Due to $\mathrm{HPS}_{2}$ lower capacity relative changes of $f_{1}$ are smaller compared to the relative changes of $f_{2}$. From Figure 6(b), it is observed that the power coordination among HPSs is well achieved. Increase in the load power of $\mathrm{HPS}_{1}$ is the overloading state of HPS ${ }_{1}$. The other HPS supports the power consumption by decreasing the DC voltages and $\mathrm{AC}$ frequencies. To match with electrical demand at $\mathrm{HPS}_{1}$, all other HPS supports and IPC are adjusting the power output according to correction coefficient $\alpha$. Since the correction coefficient $\alpha$ is different for different HPSs so the relative changes in ACfrequencies and DC voltages will be different as shown in Figure 6(c).

Figure 7(a) shows the load power where load at $\mathrm{HPS}_{1}$ is suddenly decreased from $240 \mathrm{Kw}$ to $170 \mathrm{KW}$ but load on other HPS remains constant. To cope up with the decrease in load all other IPCs will coordinate and decrease the source power according to total load demand (Figure 7(b)). The incremental source power is based upon the correction coefficient. Since the correction coefficient of all HPSs is different and based upon HPS capacity, each HPS will change power accordingly. The decrease in load results in increase in frequency and due to coordinated control alone $\mathrm{HPS}_{1}$ will not bear the major changes, the other HPS will substantially increase the frequency in specified limit which reduces the overburden on $\mathrm{HPS}_{1}$.

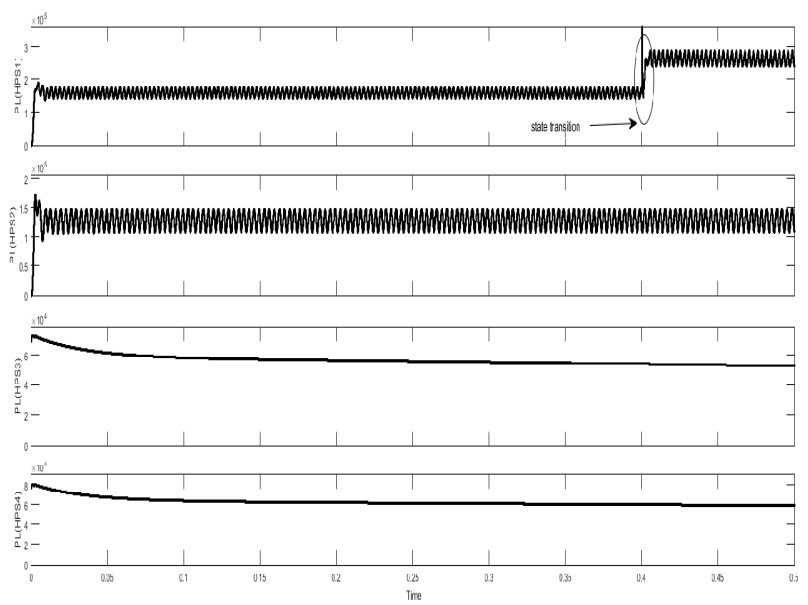

(a)
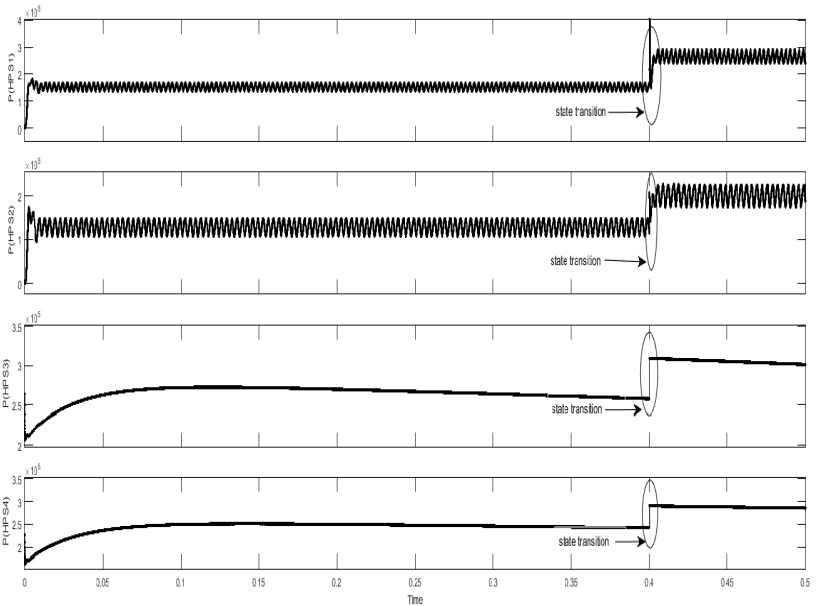

(b)

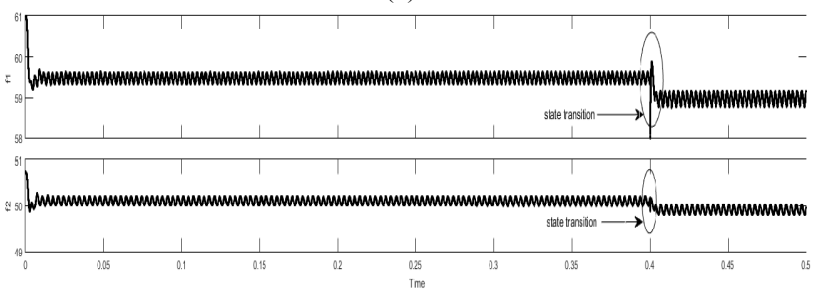

(c)

Fig. 6. Simulation results of intertied hybrid system with coordinated control (a) Load power for increase in load on $\mathrm{HPS}_{1}$ (b) Source power for increase in load on $\operatorname{HPS}_{1}$ (c) Frequency for increase in load on HPS

To additionally verify the viability of the proposed power management method, the dynamics of the intertied hybrid system are tested with changes in operating conditions of the DC $\mathrm{HPS}_{3}$. In Figure 8 the outcomes are presented. As Figure 8 shows, there are two states. The entire system operates in the stand alone mode with state I as rated state and state II as variable state. In stateII, load on $\mathrm{HPS}_{3}$ increases from $70 \mathrm{~kW}$ to $130 \mathrm{~kW}$ at $0.2 \mathrm{sec}$ under the rated DC voltage. The operation states of the other HPS in intertied HPS are not changed. Figure 8(a) demonstrates the change in load power of $\mathrm{HPS}_{3}$.As shown in Figure 8(b), due to changes in load power of $\mathrm{HPS}_{3} \mathrm{DC}$ voltages of other HPS changes in coordination, which implies that all HPSs in intertied hybrid system can support each other. 
State I represents increase in load power of $\mathrm{HPS}_{3}$, the coordination control will match the load demand with all the HPS connected in intertied hybrid system as shown in Figure $8(c)$.
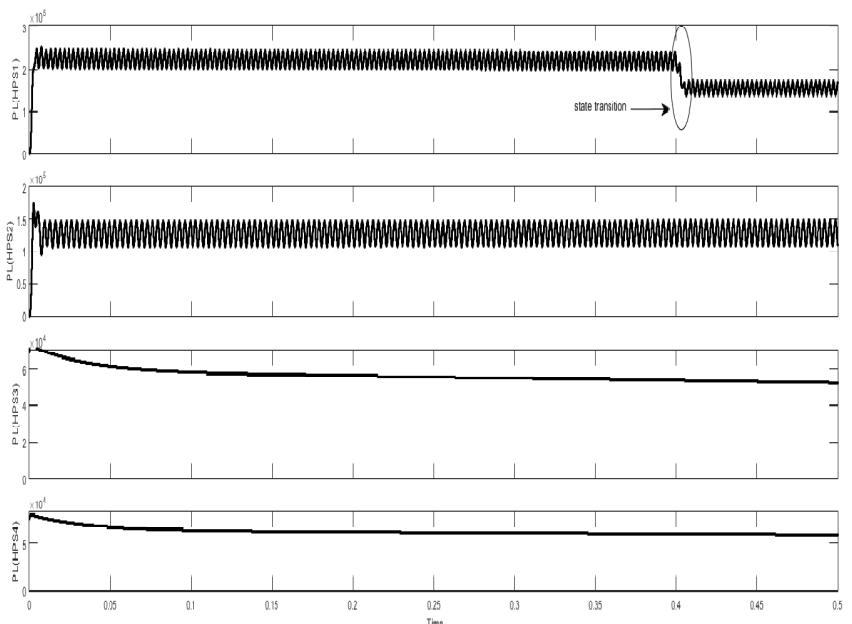

(a)
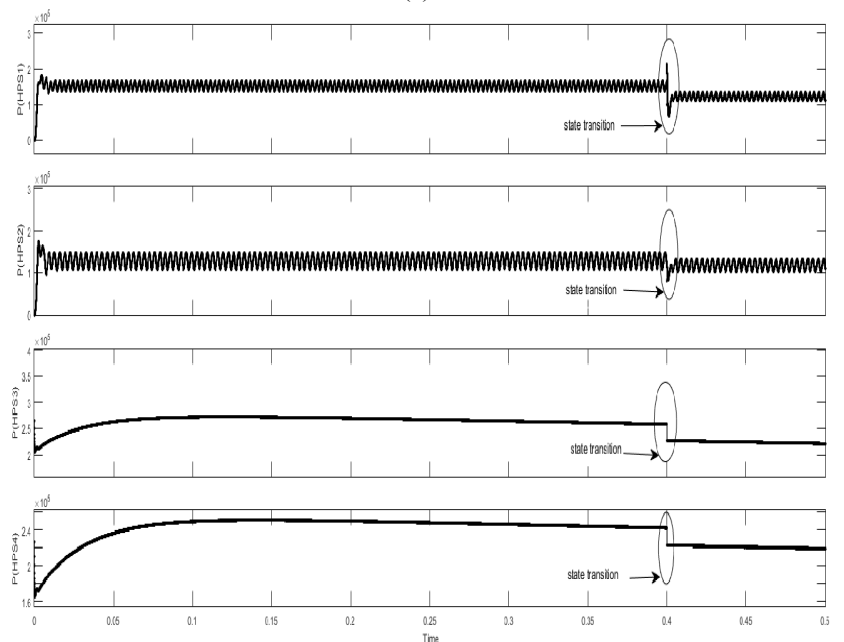

(b)

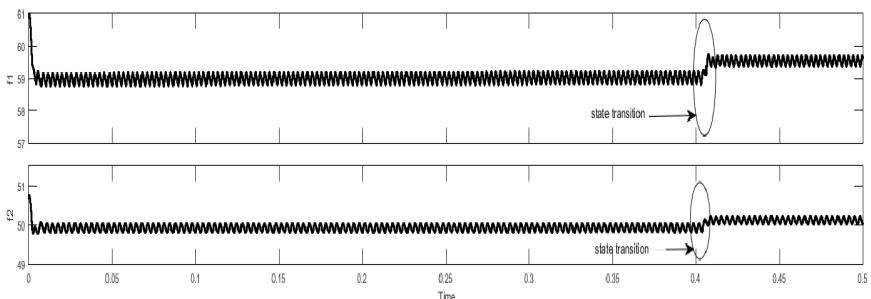

(c)

Fig. 7. Simulation results of intertied hybrid system with coordinated control (a) Load power for decrease in load on $\mathrm{HPS}_{1}$ (b) Source power for decrease in load on HPS 1 (c) Frequency for decrease in load on HPS

To show further the viability of the proposed power management method, the dynamics of the intertied hybrid system are tested with decrease in load on $\mathrm{HPS}_{3}$. Figure 9 is the outcome with the proposed control. As evident from Figure 9 the load on $\mathrm{HPS}_{3}$ decreases from $70 \mathrm{~kW}$ to $130 \mathrm{~kW}$ at $0.2 \mathrm{sec}$ under the rated DC voltage. The operating conditions of all HPS connected to intertied hybrid system are unchanged. Figure 9(a) shows the change in load power of $\mathrm{HPS}_{3}$ at $0.2 \mathrm{sec}$. from $60 \mathrm{KW}$ to $30 \mathrm{KW}$. Decrease in load at $\mathrm{HPS}_{3}$ will result in increase in DC voltage and cordinated control increases the DC voltage of other HPS proportionate to the correction coefficient. In state I when the load power of HPS decreases, due to the coordination control the source power of all HPS will decrease accordingly as shown in Figure 9(c).

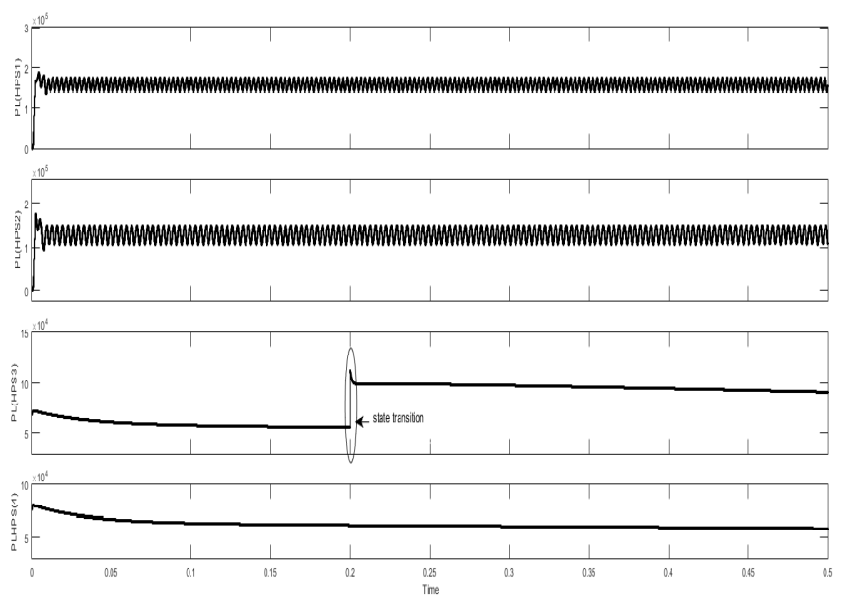

(a)

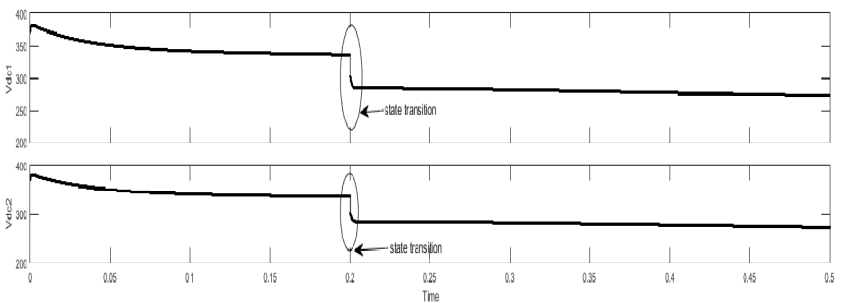

(b)
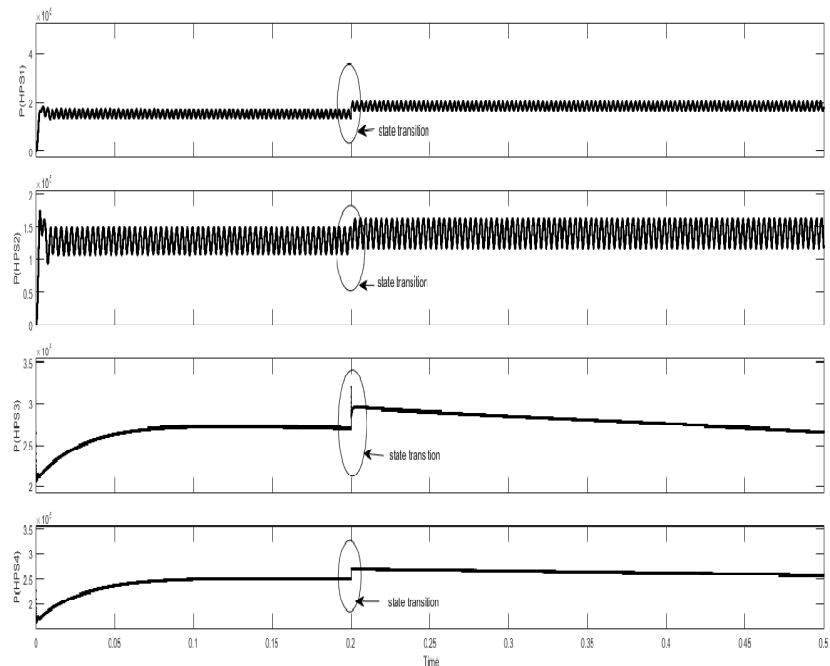

(c)

Fig. 8. Simulation results of intertied hybrid system with coordinated control (a) Load power for increase in load on $\mathrm{HPS}_{3}$ (b) Source power for increase in load on $\mathrm{HPS}_{3}$ (c) Frequency for increase in load on $\mathrm{HPS}_{3}$ 

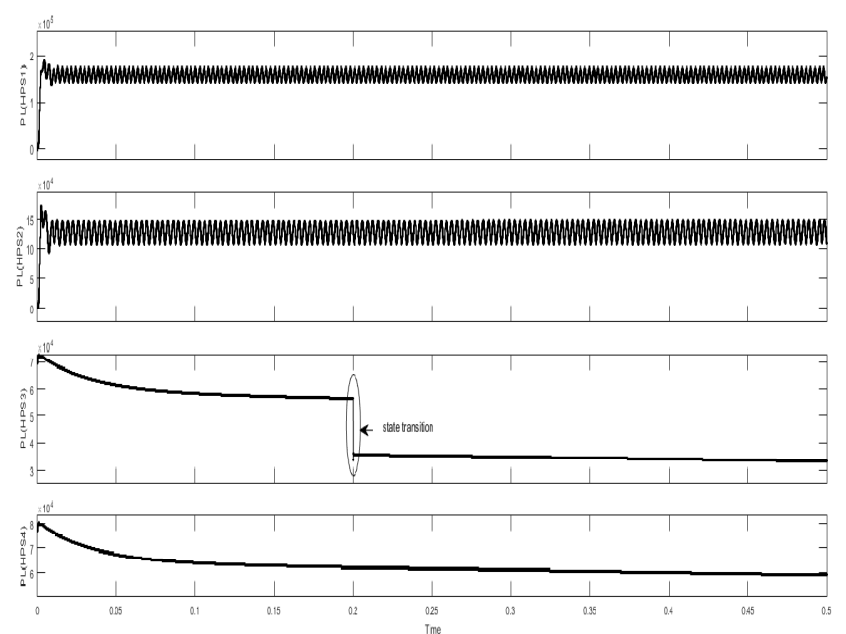

(a)

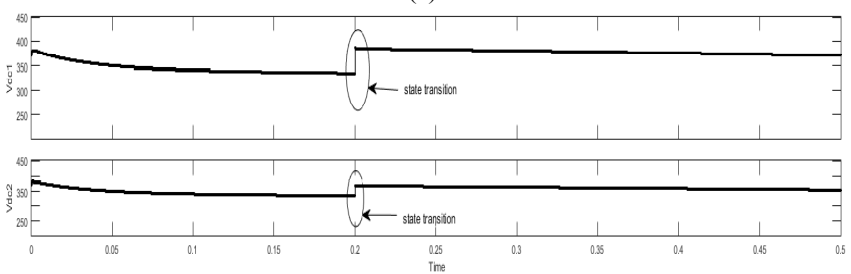

(b)
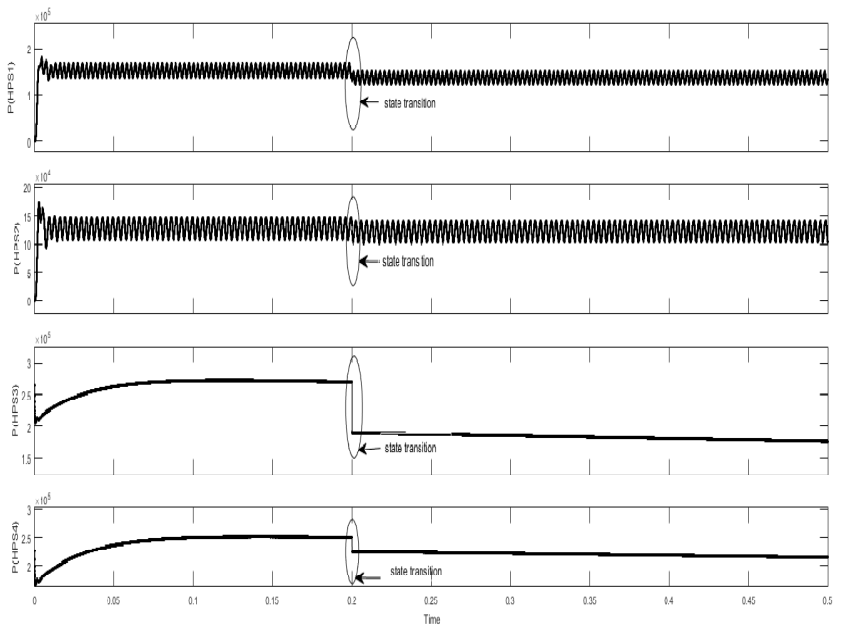

(c)

Fig. 9. Simulation results of Intertied Hybrid system with coordinated control (a) Load power for decrease in load on $\mathrm{HPS}_{3}$ (b) Source power for

decrease in load on $\mathrm{HPS}_{3}$ (c) Frequency for decrease in load on $\mathrm{HPS}_{3}$

The above mentioned results clearly show that the proposed power management method works well under different conditions and effective coordination among all HPS is achieved.

\section{CONCLUSION}

A new control technique for an intertied hybrid AC/DC system with numerous HPSs is proposed. The proposed decentralized power management method achieves good coordination among all HPSs. In respect to common bus a $\mathrm{P}_{\mathrm{dc}^{-}}$ $\mathrm{V}_{\mathrm{dc}}{ }^{2}$ droop control strategy is proposed which maintains the common bus voltage and realizes power sharing in the storage HPS. Also the coordinated power control strategy ensures interaction among multiple HPSs to look after the common bus voltage, AC frequency and DC voltage for the individual IPCs and to ensure proper power sharing. The results with coordinated control and without coordinated control are compared. The proposed control takes system capacities into consideration, which ensures the proper supply-demand and power quality of the intertied HPS.

\section{REFERENCES}

[1] M. Reza, "Stability analysis of transmission systems with high penetration of distributed generation", PhDThesis, Delft Technische Universiteit, Faculty of Electrical Engineering, Mathematics and Computer Science, 2006

[2] P. Piagi, R. H. Lasseter, "Autonomous control of microgrids", IEEE Power Engineering Society General Meeting,pp. 8-11, 2006

[3] M. C. Chandorkar, D. M. Divan, R. Adapa, "Control of parallel connected inverters in standalone AC supply systems", IEEE Transactions on Industry Applications, Vol. 29, No. 1, pp. 136-143, 1993

[4] N. Pogaku, M. Prodanovic, T. C. Green, "Modeling, analysis and testing of autonomous operation of an inverter-based microgrid", IEEE Transactions on Power Electronics, Vol. 22, No. 2, pp. 613-625, 2007

[5] D. De, V. Ramanarayanan, "Decentralized parallel operation of inverters sharing unbalanced and nonlinear loads", IEEE Transactions on Power Electronics, Vol. 25, No. 12, pp. 3015-3025, 2010

[6] M. Prodanovic, T. C. Green, H. Mansir, "A survey of control methods for parallel three-phase inverters connection",Eighth International Conference onPower Electronics and Variable Speed Drives, No. 475, pp. 472-477, 2000

[7] V. Nasirian, S. Moayedi, A. Davoudi, F. L. Lewis, "Distributed cooperative control of DC microgrids,"IEEE Transactions on Power Electronics, Vol. 30, No. 4, pp. 2288-2303, 2015

[8] P. Wang, X. Lu, X. Yang, W. Wang, D. Xu, "An improved distributed secondary control method for DC microgrids with enhanced dynamic current sharing performance,'IEEE Transactions on Power Electronics, Vol. 31, No. 9, pp. 6658-6673, 2016

[9] P. H. Huang, P. C. Liu, W. Xiao, M. S. El Moursi, “A novel droop-based average voltage sharing control strategy for DC microgrids," IEEE Transactions on Smart Grid, Vol. 6, No. 3, pp. 1096-1106, 2015

[10] X. Lu, J. M. Guerrero, K. Sun, J. C. Vasquez, "An improved droop control method for DC microgrids based on low bandwidth communication with DC bus voltage restoration and enhanced current sharing accuracy,'IEEE Transactions on Power Electronics, Vol. 29, No. 4, pp. $1800-1812,2014$

[11] V. Nasirian, S. Moayedi, A. Davoudi, F. L. Lewis, "Distributed cooperative control of DC microgrids,"IEEE Transactions on Power Electronics, Vol. 30, No. 4, pp. 2288-2303, 2015

[12] F. Nejabatkhah, Y. W. Li, “Overview of power management strategies of hybrid AC/DC microgrid,'IEEE Transactions on Power Electronics, Vol. 30, No. 12, pp. 7072-7089, 2015

[13] N. Eghtedarpour, E. Farjah, "Power control and management in a hybrid AC/DC microgrid," IEEE Transactions on Smart Grid, Vol. 5, No. 3, pp. 1494-1505, 2014

[14] M. Hosseinzadeh, F. Rajaei Salmasi, "Power management of an isolated hybrid AC/DC micro-grid with fuzzy control of battery banks,"IET Renewable Power Generation, Vol. 9, No. 5, pp. 484-493, 2015 